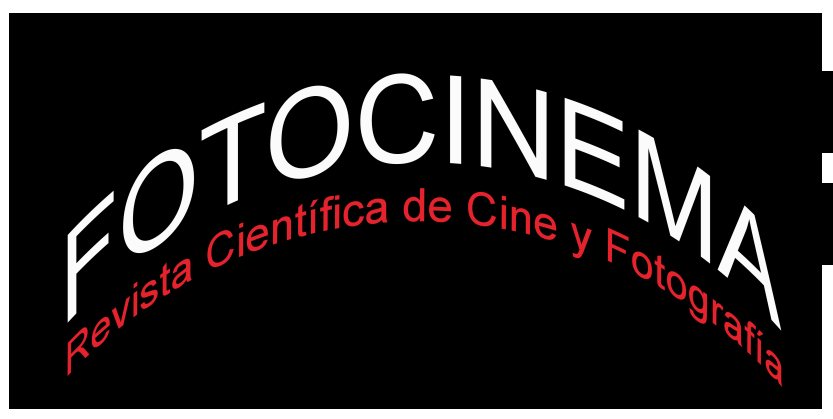

\title{
ADAPTANDO EL TERROR CINEMATOGRÁFICO A LA SERIALIDAD TELEVISIVA. EL CASO DE SCREAM
}

\section{ADAPTING THE HORROR FILM TO TELEVISION SERIALITY. SCREAM AS A CASE STUDY ANALYSIS}

Irene Raya Bravo Universidad de Sevilla, España iraya@us.es

\section{Resumen:}

Durante el nuevo milenio ha aumentado significativamente la producción de series televisivas en el ámbito estadounidense. En este contexto, el reciclaje de ideas, los remakes y las adaptaciones se han convertido en una práctica habitual en un mercado que necesita abastecerse constantemente. Entre otros medios, el cine se ha propuesto como una fuente argumental recurrente para la industria televisiva, generándose numerosas adaptaciones seriales a partir de una película. Asimismo, el mercado televisivo está marcado por la fragmentación de las audiencias y la necesidad de especialización temática, lo que favorece el traslado de todo tipo de géneros; concretamente, en los últimos años el género de terror ha generado varias adaptaciones televisivas a partir de clásicos cinematográficos. El presente artículo analiza cómo la serie Scream adapta la famosa saga cinematográfica de la que procede. El objetivo es comparar los principales cambios que se producen entre serie y película, observando las dificultades de trasladar un subgénero tan complejo como el neo slasher.

\begin{abstract}
:
During the new millennium the production of television drama has significantly increased in the US market. In this context, the recycling of ideas, remakes and adaptations have become a common practice in a market which needs to stock up constantly. Among other mass media, the cinema has been proposed as a common source of storylines for TV industry, generating many serial adaptations that derive from movies. Likewise, the TV market is characterized by fragmented audiences and specialization of contents, favouring the translation of all kind of genres; specifically, the horror genre has generated some adaptations from classic movies in recent years. This paper analyzes how the TV show Scream adapts the famous saga from which it proceeds. The aim is comparing the main changes between the TV show and the movies, noting the difficulties of translating a subgenre as complex as neo slasher.
\end{abstract}

Palabras clave: adaptación; televisión; cine; terror; Scream.

Keywords: Adaptation; Television; Cinema; Horror; Scream. 


\section{Introducción}

A partir del nuevo milenio, conocido como "la Era del Drama" (Longworth Jr., 2002; Tous, 2009, 2010), existe en el contexto televisivo estadounidense un incremento de producción que se traduce en propuestas de gran calidad, experimentación narrativa y riesgo formal. Dichas producciones se distribuyen además a gran escala de forma internacional, convirtiéndose en una "experiencia mundializada y transpantalla” (Rincón, 2013, p. 183), afectando al panorama mediático global.

La necesidad de abastecer una demanda de producción enorme fomenta el préstamo argumental entre medios y el alargamiento narrativo de los relatos, siendo una etapa caracterizada por la proliferación de remakes, spin-off, prolongaciones diegéticas (precuelas y secuelas) y, por supuesto, adaptaciones. El uso de este tipo de fórmulas es práctico, sobre todo desde un punto de vista comercial, porque se reutilizan personajes, espacios y relatos conocidos por el público, asegurando en gran medida su aceptación. Refiriéndose concretamente al remake, pero perfectamente asumible para todas estos textos que expanden el relato original, el investigador Constantine Verevis asevera que estas propuestas son productos industriales que aseguran cierta garantía comercial (2006, p. 3).

El presente artículo analiza cómo el medio cinematográfico también se ha convertido en una fuente argumental para la ficción televisiva, realizándose numerosas adaptaciones que parten de una película. La fragmentación del público ha derivado en una mayor especialización temática, favoreciendo el traslado de todo tipo de géneros en distintos formatos de ficción televisiva. Con la intención de centrar el campo de estudio se han escogido aquellas adaptaciones que se adscriben al género de terror, pues las singularidades de esta forma genérica propician un análisis rico e interesante. Asimismo, con el objetivo de ver cómo se concreta este traslado en un caso específico se analiza la serie Scream (MTV: 2015-), observando cómo se adapta la franquicia cinematográfica de la que procede a la pequeña pantalla. 


\section{Marco teórico}

\subsection{La ficción de terror en el contexto televisivo estadounidense}

Antes de abordar la producción de ficción serial de terror es necesario señalar las singularidades del género, ya que posee una serie de cualidades que lo convierten en un caso especial dentro la producción televisiva. Cuando se habla de este concepto, generalmente se atiende a cuestiones de temática, tratamiento y estructura, es decir, que cuando un grupo de textos organiza las piezas semánticas (temas y tramas comunes, tipos de personajes, objetos familiares, sonidos reconocibles, tipos de planos, escenas clave) y sintácticas (estructura de la trama, las relaciones entre personajes, montaje) de forma similar es cuando aparece realmente el género (Altman, 2000).

A través de los géneros, como ya sucede en otros medios como la literatura y el cine, el discurso televisivo ordena los contenidos y crea patrones reconocibles para el espectador, quedando así integrados los nuevos productos en una estructura familiar. Es una noción que sobrepasa al propio texto como constructo único, pues lo inscribe en un discurso mayor que va desarrollándose y transformándose a lo largo del tiempo, de manera que lo géneros funcionan como eslabones mediante los cuales la obra se relaciona con el universo en el que se inserta (Todorov, 2005, p. 11).

No obstante, a diferencia de otras fórmulas hermanas con las que puede compartir contenidos extraordinarios, como la ciencia ficción y la fantasía, el terror como género funciona de forma particular, porque su designación no se debe especialmente ni a estructuras narrativas, ni a tipos de puesta en escena, como tampoco corresponde con una serie de ideas; el terror se fundamenta principalmente en el efecto emocional que despierta en su audiencia, especialmente miedo y angustia (Sánchez-Noriega, 2003, p. 153).

Como género emerge a través de la literatura gótica en el siglo XVIII, especialmente en el contexto inglés, francés y alemán, datándose específicamente la consolidación del terror moderno durante el Romanticismo. El género de terror se posiciona como una forma esencial de 
reflejar estados de ansiedad y preocupaciones sociales a lo largo de la historia, ofreciendo un lugar de experimentación artística sin parangón, pues se adapta continuamente al devenir histórico, mostrando los cambios de sensibilidad artística, las pulsiones eróticas y los preceptos morales e instituciones que se van volviendo obsoletos (Jenkins, 2007, p. 45). Cuando se vincula al relato inverosímil, el monstruo es el personaje más común dentro del género de terror, en cualquiera de sus formas (vampiro, zombi, momia, hombre lobo, fantasma, brujas...), pero a diferencia de los seres extraordinarios de la fantasía, estos deben provocar disgusto o desagrado al lector/espectador; asimismo tampoco deben resultar familiares para los otros personajes que pueblan el mundo narrado, por lo que producen una desestabilización del orden natural de las cosas (Carroll, 1990, pp. 16-22). Además de los personajes, existe también un largo repertorio de espacios vinculados al género (mansiones y castillos encantados, cabañas en el bosque, pueblos abandonados, psiquiátricos y hospitales...), produciéndose en muchos casos la desvirtuación del espacio normal o doméstico, que deja de ser un lugar familiar para convertirse en un sitio amenazante e inestable.

Debido a sus particularidades, no es un género especialmente cultivado en la historia de la televisión estadounidense como forma serial, aunque ha estado presente desde los orígenes del medio hasta la actualidad. Con la finalidad de evitar una marcada serialidad como la que caracteriza al dramático, se han usado preferentemente dos tipos de formatos marcados por su verticalidad argumental: por un lado, la tv movie o telefilm, que son aquellas películas creadas directamente para su exhibición en televisión. Desde el punto de vista de la fragmentación de las tramas, las tv movies guardan pocas semejanzas con el resto de la ficción televisiva, ya que no tienen una conexión argumental. No obstante, es un formato muy prolífico que también incluye numerosos remakes de productos exitosos. Tal es el caso de gran parte de las obras literarias de Sthephen King, que son trasladadas al ámbito audiovisual de forma frecuente, generalmente como telefilmes pero también abriendo espacio a los dramáticos ${ }^{1}$.

1. Los títulos de telefilmes basados en sus obras son muy numerosos, comenzando a 
Por otro lado se encuentra la antología, refiriéndose a aquellas series configuradas episódicamente y con capítulos independientes sin nexo argumental común, que se vinculan por razones de género o tema. El formato antológico, sea cual sea el momento histórico en el que se desarrolla, se propone como un formato ideal para plantear metáforas, siendo muchos son los ejemplos prácticos que utilizan elementos sobrenaturales (monstruos, profecías, personajes, etc.), especialmente dentro del dominio del terror para connotar conflictos sociales y humanos (Sánchez-Noriega, 2003, p. 153).

En ese sentido, Dimensión desconocida (The Twilight Zone, CBS: 1959-1964) es una de las series pioneras que mejor refleja esta línea simbólica. Creada por el guionista Rod Serling, en ella se combinan temas propios del horror, la fantasía o la ciencia ficción en cada una de sus entregas, pero siempre con la intención de crear alegorías sobre problemáticas reales de la época, conectando por completo con las inquietudes de su audiencia. La serie tuvo tal éxito que provocó el lanzamiento de propuestas similares con el mismo propósito reflexivo, como es el caso de Rumbo a lo desconocido (The Outer Limits, ABC: 1963-1965), que seguirá esta línea de capítulos autoconclusivos, focalizando sus líneas temáticas dentro de motivos más cercanos a la ciencia ficción. Años después Serling continúa creando dentro de este formato pero decantándose por el terror puro, adaptando libremente clásicos de H.P. Lovecraft e historias propias con una nueva antología llamada Galería Nocturna (Rod Serling's Night Gallery, NBC: 1969-1973). Durante la década de los ochenta se estrena Cuentos asombrosos (Amazing Stories, NBC: 19851987), Historias de la cripta (Tales from the Crypt, HBO, 1989-1996) y la nueva versión de Más allá de los límites de la realidad (The Twilight Zone, CBS: 1985-1989). Durante el nuevo milenio se rescata el formato lanzando la antología Maestros del terror (Masters of Horror, Showtime: 2005-2007) en la que cada capítulo es dirigido por un director célebre del cine de terror. Con American Horror Story (FX: 2011-) se recupera el concepto de antología de terror y ciencia ficción de los años cincuenta, pero se actualiza el concepto, y

producirse a finales de los 80 hasta el momento presente. En cuanto a su adaptación al dramático, en los últimos años se ha vuelto más significativa su producción como prueban: La zona muerta (The Dead Zone, USA Network: 2002-2007); Haven (SyFy: 2010-), inspirada en su novela Colorado Kid (2005) y La Cúpula (Under the Dome, CBS: 2013-). 
en lugar de realizar capítulos independientes se realizan temporadas completas autoconclusivas con líneas temáticas diferentes a modo de serie limitada como antología ${ }^{2}$ - hasta el momento actual han sido cinco: Murder House, Asylum, Coven, Freak Show, Hotel; cada una de ellas está relacionada con iconografía y temáticas propias del horror contemporáneo, mezclándose con otros motivos de la fantasía, la ciencia ficción o de las ficciones realistas, dando como resultado un texto heterogéneo y difícil de clasificar desde el punto de vista del género.

En cuanto al formato dramático, aunque no sea un género tan cultivado, se han producido también últimamente seriales de terror con contenido fantástico; destacan aquellos en los que se emplean tópicos del terror sobrenatural que están muy asimilados en el imaginario colectivo de la audiencia, especialmente vinculados a espacios o personajes. Es el caso de Penny Dreadful (Showtime: 2014-2016), adscrita al horror en el contexto de la Inglaterra victoriana, y que incluye numerosas figuras de la literatura clásica del siglo XIX: Dorian Gray, de la novela de Oscar Wilde, El retrato de Dorian Grey (1890); el Dr. Frankenstein y Frankenstein, personajes habituales en las fábulas contemporáneas; o Drácula y Mina, de la obra epistolar ya mencionada de título homónimo. Por su parte, Salem (WGN America, 2014- ) también retorna al pasado en su vertiente más gótica, ubicando la acción en esta famosa ciudad norteamericana asociada a la brujería y contextualizada en el siglo XVII, exponiendo un relato sobrenatural de misterio y magia negra. Algunas ficciones actualizan la imagen de los monstruos clásicos y los trasladan al presente, tal y como se comprueba en True Blood (HBO: 2008-2014), en donde coexisten vampiros y hombres lobos con brujas y hadas, o Hemlock Grove (Netflix, 2013-2015), más centrada en la licantropía.

\footnotetext{
2. Las series limitadas se encuentran a medio camino entre el dramático y la miniserie. Su parecido más cercano se establece con las Limited Series de los cómics, que son historias autoconclusivas paralelas a las grandes colecciones con una duración limitada y con carácter de exclusividad. Desde 2015 los premios Emmy han transformado el nombre de la categoría, motivado sin duda por la creciente importancia de este nuevo formato. Véase la nota de prensa de los premios de la $67^{\text {th }}$ EMMY AWARDS NOMINATIONS en donde se especifica que "The Outstanding Miniseries category was redefined this year as Outstanding Limited Series". Disponible en http://www.emmys.com/sites/default/files/Downloads/67th-nominations-list-v1.pdf (Consultado el 18-9-2016).
} 
Es curioso como en muchos casos se pone en práctica la fusión entre terror y ciencia ficción, pues esta es una forma de hibridación anclada en las más profundas raíces del género, ya cultivada en los clásicos literarios de Mary Shelley y Edgar Allan Poe. El objetivo de estos escritores era provocar miedo al lector, apoyándose en monstruos, seres antinaturales y atmósferas opresivas, que son elementos comunes dentro del género, e introduciendo también extraños adelantos tecnológicos y alarmantes teorías científicas futuristas, que más tarde se asociarían a la ciencia ficción. La televisión lleva esta mezcolanza a sus últimas consecuencias como demuestra la nueva versión de Dracula (NBC: 2013-2014), donde la ciencia moderna tiene cierto protagonismo. Otro ejemplo lo propone la extraña visión que Guillermo del Toro presentación de la vampirización como enfermedad vírica en The Strain (FX: 2014- ).

\subsection{Adaptando el terror del cine a la televisión}

Las adaptaciones de cine a televisión dentro del género de terror no han representado una práctica relevante ni con gran recorrido histórico en la programación televisiva estadounidense. Desde la entrada del nuevo milenio sí se ponen en marcha más iniciativas de este tipo, recuperando éxitos cinematográficos de terror que tratan de trasladarse a la televisión. Este fenómeno de reciclaje, que consiste en reinterpretar los textos originales, consigue crear además "efectos nostálgicos -por la recuperación de materiales audiovisuales del pasado" (Gordillo, 2009, 18); se debe vincular esta corriente al auge de la ficción nostálgica, muy asociada al género de terror, y en donde se concede gran importancia a la autoreflexividad (Leeder, 2009).

Entroncando con fórmulas dirigidas al público adolescente, que se ha convertido en un sector de la audiencia muy atractivo, la cadena MTV ha rescatado títulos cinematográficos de gran aceptación popular como sucede con Teen Wolf (2011-), cuya base argumental es la famosa producción protagonizada por Michael J. Fox Teen Wolf. De pelo en pecho (Teen Wolf, Rod Daniel, 1985), manteniendo los nombres de algunos personajes y la importancia del deporte en sus vidas (baloncesto aquí y lacrosse en la serie); 
asimismo el canal ha continuado trabajando dentro de esta tendencia, trasladando a la pequeña pantalla la famosa saga de los 90 Scream -caso de estudio seleccionado para el presente artículo.

El cineasta Robert Rodríguez también se ha lanzado al mercado televisivo con la serie Abierto hasta el amanecer (From Dusk Till Dawn: The Series, El Rey Network: 2014- ). Dicha producción es una adaptación de su propia película Abierto hasta el amanecer (From Dusk Till Dawn, Robert Rodríguez, 1995), cuyo guión firmaba Quentin Tarantino; en la serie se conservan los mismos personajes que se hicieron populares en la película de vampiros mejicanos así como se mantienen momentos icónicos como el baile de tintes eróticos de Satánico Pandemonium. Aunque su origen es literario, el éxito del clásico de terror El exorcista (The exorcist, William Friedkin, 1973) es el que propicia la recuperación del argumento para televisión, trasladándose a la pequeña pantalla El exorcista (The Exorcist, Fox: 2016- ).

No obstante, la fusión frecuente en la ficción televisiva favorece la creación de obras genéricamente mestizas, susceptibles de atraer a un público diverso. Sin duda, uno de los casos de hibridación más habituales se produce entre el terror y el thriller, siendo además este último un género muy fecundo en esta "Era del Drama", en gran medida porque el contenido del relato se adapta muy bien al formato episódico. En esta línea, se aprovecha el interés por mostrar el pasado de emblemáticos asesinos en serie que alcanzaron la fama en el cine, quedando reflejado en diferentes precuelas televisivas que retratan sus orígenes. Así el espectador es testigo de la extraña adolescencia de Norman Bates en Bates Motel (A\&E, 2013-) antes de convertirse en el temible asesino con trastorno disociativo de la identidad en Psicosis (Psycho, Alfred Hitchcock, 1960); asimismo, se descubren las conexiones entre Hannibal Lecter y Will Graham en Hannibal (NBC: 2013-2015) antes de ser atrapado por el agente del FBI -primero en Hunter (Manhunter, Michael Mann, 1986) y después en el remake El dragón rojo (1981)- y antes de atormentar a Clarice Starling en la exitosa El silencio de los corderos (The Silence of the Lambs, Jonathan Demme, 1991). 


\subsection{Dificultades de la adaptación televisiva}

La adaptación de obras a distintos medios suele ir acompañada de cierto rechazo crítico, pues el reciclaje de textos puede interpretarse de forma negativa, como el desgaste consecuente de la escasa capacidad de innovación de las entidades emisoras. No obstante, desde esta óptica no se contempla la renovación y la incesante evolución del concepto "originalidad" que se vive desde finales del siglo XX. En este nuevo contexto cultural, el mito del valor único de la novedad es sustituido por un nuevo paradigma, pues las "ficciones de la repetición” (Balló y Pérez, 2005), como las series o las adaptaciones, poseen originalidad por su potencialidad para desplegarse y vincularse con otros relatos y universos narrativos.

Es constatable que desde una perspectiva histórica sea frecuente en el ámbito cinematográfico que otros materiales como las novelas, los cómics o los videojuegos sirvan de base para la creación de producciones fílmicas. En las últimas décadas ha resultado ser una práctica muy rentable la adaptación de extensas sagas literarias como El señor de los anillos, Harry Potter o Crepúsculo3, o el traslado a la pantalla de universos que surgieron en los cómics más famosos de Marvel y DC. Las franquicias cinematográficas, a través de sus múltiples y sucesivas entregas, arreglaron uno de los mayores problemas de las adaptaciones a la gran pantalla, que era la supresión o la concentración de numerosos elementos de la historia.

En cambio, la televisión parte con esa ventaja frente al medio cinematográfico, ya que la historia puede desarrollarse de forma detallada, durante años, en capítulos de aproximadamente una hora, siendo posible incluso añadir nuevas situaciones o personajes. En definitiva, "es como si la doble función de a) larga duración y b) estructura en bloques, propia del discurso serial televisivo, permitiera una mayor flexibilidad para no tener que ceñirse a la lógica de condensación que impone el discurso fílmico

\footnotetext{
3. Publicación de las novelas: El señor de los anillos (1954-1955), Harry Potter (1997-2007) y Crepúsculo (2005-2008). Adaptación cinematográfica: El señor de los anillos (2001-2003), Harry Potter (2001-2011) y Crepúsculo (2008-2011).
} 
estándar" (Díaz, 2012, p. 507). No obstante, tal y como sucede con el cine, las relaciones que se establecen entre las obras originales y sus adaptaciones seriales suelen generar polémica, pues en ocasiones la nueva propuesta se distancia del texto primario, ya sea por necesidades productivas, narrativas o tecnológicas, suprimiendo o añadiendo lo que considere necesario.

Se han propuesto diferentes clasificaciones según el grado de correspondencia que exista entre el texto literario y la adaptación fílmica, siendo uno de los estudios esenciales el que realiza Geoffrey Wagner en The Novel and the Cinema (1975). El autor propone tres categorías básicas que también son válidas para analizar textos televisivos: en primer lugar, la "transposición”, asociada a las adaptaciones más fieles en las que los cambios son poco significativos; en segundo lugar, el "comentario", que se produce cuando se introducen variaciones más notables; y en último lugar, la “analogía”, en la que el interés es crear una obra diferente de manera que las novedades que se introducen son considerables. En televisión es habitual que una serie empiece con intención de trasposición y acabe convirtiéndose en un comentario, pues las exigencias del medio, sobre todo temporales, requieren la introducción de nuevos personajes o situaciones para alargar el tiempo del discurso o para solventar problemas de ritmo.

Centrando el interés en el tema de estudio concreto, siendo la trasposición de película a serie, la problemática que se presenta es muy particular. A diferencia de lo que sucede con las novelas y los cómics, que poseen un marcado carácter serial, el formato cinematográfico que no se integra en grandes franquicias o sagas, difiere mucho del televisivo, lo que se traduce en que la adaptación de una película conlleva siempre inevitables modificaciones. Por un lado, la menor duración del tiempo de discurso en una película va a modificar inevitablemente la historia madre que se adapte a televisión, exigiendo muy probablemente la creación de líneas argumentales nuevas, la inclusión de un mayor número de personajes e inevitables discrepancias con respecto al texto original. Por otro lado, el formato dramático suele estructurarse tanto a través de tramas episódicas como 
seriales, lo que introduce una necesidad narrativa que no se produce en el formato fílmico.

Sin duda, esas peculiaridades discursivas van a limitar las posibilidades de la adaptación, lo que obviamente va a modificar el contenido o la forma del texto original, siendo difícil encontrar casos puros de transposición.

\section{Metodología}

Para realizar este estudio se parte de un análisis cualitativo del discurso audiovisual, prestando especial atención a conceptos procedentes de las siguientes disciplinas: Teoría, Historiografía y Crítica Televisiva, pues los objetos de estudio se enmarcan en un contexto histórico de producción muy determinado; Teoría de los Géneros, con el fin de observar las cualidades del terror así como los procesos de hibridación contemporáneos; Adaptación Fílmica y Literaria, reutilizando nociones también compatibles del medio televisivo; Narrativa Audiovisual, que provee de las herramientas necesarias para realizar el análisis de la serie; y por último, los Estudios Culturales, viendo como los diferentes contextos históricos pueden afectar en la construcción del nuevo texto. El proceso de análisis se divide en tres fases que enmarcan las principales posibilidades de transformación entre película y serie:

- En primer lugar, se realiza un análisis narrativo comparativo entre película y serie que tenga en consideración diferentes aspectos, resumidos por López-Rodríguez (2012, p.1555) en los siguientes tipos de cambios: añadido, supresión y cambios (modificación, compresión y desarrollo) de elementos que varían con respecto al texto de partida. Siguiendo esta fórmula, se comprueba si hay variaciones con respecto a ambientes y personajes, así como la reproducción de escenas icónicas del texto original; en segunda instancia, se comprueba si existe una actualización del contexto temporal; por último, la inclusión o eliminación de tramas argumentales secundarias, viendo si se producen los llamados efectos de "expansión” (ampliación narrativa de la historia) o “compresión 
narrativa” (supresión de elementos del relato original) (Scolari, Jiménez y Guerrero, 2012, p. 160)4.

- A continuación, se estudia si se respetan las convenciones de género, especialmente aquellas vinculadas al terror, o si la serie ha sufrido una transformación con respecto a la obra fílmica que adapta. En una época televisiva tan marcada por el fenómeno de hibridación, en la que existe una tendencia creciente hacia la fusión y la mezcla (Mittell, 2004; Ribés, 2005; Gordillo, 2009; Tous, 2010), es imprescindible analizar si en ese proceso de adaptación se respeta el tono del texto original o si, por el contrario, presenta modificaciones.

- Por último, se observa si las producciones seleccionadas funcionan como “transposición”, “comentario”, “analogía” (Wagner, 1975).

Como caso de estudio, se ha escogido la serie de televisión Scream, cuyo origen es una famosa saga de terror adolescente iniciada con la película Scream: Vigila quién llama (Scream, Wes Craven, 1996), que actualmente cuenta con otras tres entregas: Scream 2 (Wes Craven, 1997), Scream 3 (Wes Craven, 2000) y Scream 4 (Wes Craven, 2011). La elección de este caso estudio se fundamenta en tres variables principales:

1. La serie parte directamente de una producción cinematográfica, evitando aquellos ejemplos, mucho más numerosos, que fueron novelas antes de materializarse como películas.

2. En segundo lugar, la intención es comprobar si se ha producido un reajuste del contexto temporal, pues la saga cinematográfica se desarrolla durante un periodo superior a 10 años y la trama se adapta a su tiempo mientras que la serie se ha realizado en un lapso menor -entre los años 2015-20165.

\footnotetext{
4. En su estudio, los autores utilizan los conceptos de "expansión" y "compresión" para referirse al desarrollo transmediático de un universo, centrados en las adaptaciones entre distintos formatos. No obstante, su terminología resulta interesante aplicada a la adaptación de formatos aunque no implique una ampliación transmediática. Véase también (Scolari, 2013).

5. A pesar de su discreta audiencia, la serie ha renovado por una tercera temporada, y además se han realizado dos capítulos especiales para Halloween de 2016.
} 
3. Por último, se escoge un caso cuyo uso del terror oscila entre la vertiente sobrenatural y el cine de asesinos en serie convencional, pues a pesar de que detrás de la máscara de los asesinos se esconde una persona aparentemente normal, sus hazañas y su capacidad de supervivencia sobrepasan los límites de lo verosímil, vinculándose al horror más sobrenatural. La serie escogida juega deliberadamente con el concepto de "lo fantástico" desarrollado por Tzvetan Todorov (2005), pues parece debatirse entre "lo extraño" (explicación razonable dentro la lógica de nuestro mundo) y "lo maravilloso" (explicación sobrenatural). En ese sentido, aunque Scream puede analizarse como un texto adscrito al thriller, pues muestra las acciones de un asesino en serie corriente, sus proezas son casi extraordinarias, mostrándose como seres con habilidades únicas, conocimientos omniscientes y un gran don para la ubicuidad.

\section{Exposición de resultados}

\subsection{Análisis de la serie televisiva Scream}

Si se compara el contexto extradiscursivo de serie y película se comprueba que ambas producciones audiovisuales surgen con distintas necesidades comerciales. Desde el punto de vista de la producción, la película supuso la recuperación de un género poco cultivado en el cine desde mediados de los 80 -el slasher-, provocando la aparición de un ciclo de películas similares durante la década de los 90 -el neo slasher. Por otro lado, la puesta en marcha de la ficción televisiva parte de la búsqueda, por parte del canal MTV, de consagrar su producción de ficción para el público adolescente y dejar de ser etiquetada como "cadena musical". De esta forma, y siendo consciente del éxito de la franquicia, el canal eligió este texto icónico para construir su propia serie, sabiendo que despertaría el interés de los fans de la saga.

Desde la óptica discursiva, el argumento es exactamente el mismo en ambas producciones: se relata cómo una joven adolescente empieza a ser atormentada, al principio telefónicamente, por un asesino enmascarado que 
va aniquilando a distintas personas de su entorno. Los conocimientos del asesino sobre la protagonista y sus amigos siembran la duda sobre su identidad, desconfianza que se transmite al espectador que trata de averiguarlo al mismo tiempo que los personajes.

En lo referente al estudio de personajes, Sidney Prescott (interpretada por Neve Campbell) es la protagonista absoluta de la franquicia cinematográfica Scream, siendo sustituida en la ficción televisiva por Emma Duvall (Willa Fitzgerald). Aunque posean distinto nombre, ambas comparten, desde el punto de vista del rol, una serie de cualidades comunes: las dos provienen de entornos familiares conmocionados por una tragedia que marcará su futuro y, asimismo, son atormentadas hasta la locura, aunque las dos acaban venciendo al demostrar una valentía excepcional. Ambas representan el modelo clásico de "final girl", término acuñado por Carol J. Clover a finales de los 8o, refiriéndose en gran medida a las supervivientes del cine slasher de $\operatorname{los} 70$ y 80. El concepto hace alusión al personaje femenino que finalmente consigue sobrevivir tras soportar todo el sufrimiento posible, incluyendo las persecuciones, los ataques y el tormento por parte del asesino (Clover, 1987, p.201). La investigadora hace distinción entre la contraposición que se establece entre el asesino, el hombre cuya furia es de origen inequívocamente sexual, y las víctimas, mujeres jóvenes y hermosas que muestran una sexualidad libre (1987, p. 205). El subgénero slasher se caracteriza así por la representación arquetípica de asesinos varones, mujeres indefensas como víctimas, y una proliferación de desnudos, sexo y violencia gráfica (Welsh, 2009). No obstante, como se introducirá en el análisis del género, la película Scream se integra dentro de una corriente posterior basada en la reinvención denominada neo slasher, en donde el rol de la "final girl", la exhibición de la sexualidad o la tendencia hacia lo gore han sido transformados o sustituidos por la autoconciencia, e incluso, por cierto tono paródico. De esta forma, la saga consigue expresar preocupaciones sociales de los años 90, realiza un singular tratamiento del villano y muestra una "final girl" más progresista y revolucionaria (Wee, 2006, p.50). 
Como ya hacía Sidney en la película, Emma se rodea de un grupo de amigos en los que confía, habiendo ciertos paralelismos incluso entre algunas personalidades. El personaje de Randy (en la película interpretado por Jamie Kennedy) guarda conexiones con Noah Foster (John Karna), pues ambos representan roles más marginales, son fanáticos del terror y conocen "las reglas cinematográficas del cine de terror" utilizadas en las películas del género. De esta forma, Randy y Noah piensan que pueden anticiparse a los movimientos del asesino y salvar así a sus amigos. No obstante, a diferencia de lo que sucedía con Randy, Noah se convierte en un superviviente fundamental, erigiéndose en una especie de narrador autodiegético de su propia historia a través de su podcast La Morgue. Para resaltar las conexiones intertextuales entre película y serie sí que se ha reproducido el rol del villano, revelándose al final de la segunda temporada que Kieran (Amadeus Serafini), el novio de Emma, es uno de los asesinos, operando además con la misma frialdad y mostrando un perfil de psicopatía similar al que ya demostraba Billy (Skeet Ulrich) en la primera entrega de Scream.

En la serie se produce un renombramiento del espacio, pues la localidad de Woodsboro es sustituida por Lakewood, aunque se mantienen las características definidoras del mismo: es una pequeña ciudad suburbial estadounidense, formada por barrios residenciales con casas individuales y algunos espacios públicos de reunión social o vida institucional (plaza, comisaria, ayuntamiento, etc.). Tal y como sucede en la primera película, la principal localización en la que desarrollan los acontecimientos es el instituto, epicentro dramático en el que convergen la mayor parte de los asesinatos, lo que entronca directamente con que la mayoría de personajes son adolescentes. Lakewood es retratado como un lugar tranquilo e incluso festivo, formando parte de un prototipo común dentro de las ficciones adolescentes, donde los asesinatos o las desgracias no acaban de modificar el entorno idílico; de esta forma, el espacio parece recomponerse después de cada ataque, permitiendo que la vida continúe con cierta normalidad para los supervivientes. Estas pequeñas ciudades se han convertido en un topoi común en la ficción adolescente, reproduciéndose el mismo caso en Crónicas vampíricas (The Vampire Diaries, CW: 2009- ) con la localidad de Mystic 
Falls o con Chance Harbor en El círculo secreto (The Secret Circle, CW: 2012-2012). La diferencia con las entregas cinematográficas de Scream es que en cada una de ellas varía la ubicación, produciéndose el retorno al origen en Scream 4, pero la serie se desarrolla esencialmente en un solo escenario, por lo que la catarsis no puede ser igual de destructiva.

La disimilitud básica entre formatos se produce por las distintas necesidades de desarrollo, pues durante las películas el espectador es consciente de la maduración de Sidney Prescott, desde el instituto hasta su integración laboral años después mientras que, en el caso de Emma, se ha retratado hasta el momento únicamente su última etapa en el instituto. En significativo cómo la ficción televisiva, empleando muchas más horas de metraje, se mantiene en una especie de estado de suspensión, dilatando el tiempo de discurso, retrasando en la medida de lo posible el proceso de crecimiento del personaje principal. Se entra dentro de la expansión deliberada del relato, conociendo mucho más la rutina de Emma que la de Sidney Prescott, del mismo modo que el espectador desarrolla un vínculo más estrecho con los personajes secundarios al mostrarse más tramas sobre los mismos y sobre sus allegados.

Uno de los aspectos más controvertidos en cuanto a la adaptación ha sido la máscara empleada por el asesino -conocida como Ghostface-, pues ésta se convirtió en el icono visual más reconocible de la saga, provocando una gran sorpresa al espectador ante la sustitución de la misma. Aunque existe mucha semejanza entre ambos modelos y su diseño blanco e inquietante evoca otras máscaras asociadas al terror -como la máscara de hockey del asesino Jason de la saga Viernes 13 o la de Michael Myers en la franquicia de Halloween-, las diferencias entre ambos prototipos son visibles. Este cambio ha sido intencionado, tal y como explica Jamie Plagia (Murphy, 2015), uno de los showrunners originales de la serie, pues el objetivo era precisamente desvincular esa máscara tan icónica de sus personajes y de su mundo, haciendo una clara separación entre ambos productos.

Otra de las cuestiones más interesantes de la serie es el interés constante por mostrar el contexto histórico presente, en el que las nuevas tecnologías 
adquieren gran importancia, influyendo incluso en el desarrollo de la trama. Si la saga cinematográfica volvió crucial la presencia del teléfono como elemento constituyente del horror, en la serie televisiva las posibilidades de los nuevos medios incrementan las opciones de tormento por parte del asesino. Ya en Scream 4, la última entrega de la franquicia, se ponía de relieve la importancia de las redes sociales y los nuevos medios, pero su uso no estaba tan integrado como sucede con el caso televisivo. En la serie, los adolescentes se comunican constantemente a través del servicio de mensajería del móvil y videollamadas, así como las redes sociales sirven para que los propios homicidas compartan sus videos y chantajeen a los jóvenes protagonistas. No obstante, las nuevas tecnologías también son de utilidad para los personajes, que utilizan los móviles como linterna, grabadora, o incluso como vehículo de desahogo para contar las propias experiencias, tal y como hace Noah con su podcast; la importancia de los nuevos medios se expresa también visualmente, concediendo numerosos planos a la pantalla del móvil, ordenador, tablets, etc. Por consiguiente, es una serie completamente conectada a un momento histórico determinado, donde las relaciones entre los personajes dependen, en gran medida, de las conexiones que establecen a través de las nuevas tecnologías.

En cuanto al género, la serie se inserta dentro de la corriente neo slasher, siendo este un subgénero profundamente autoreflexivo sobre el propio cine slasher de los 70 y 80, cuya decadencia se produjo por el propio agotamiento de la repetición de la fórmula (Wee, 2006, p. 53). Curiosamente, esta tendencia que surge en los 90 es introducida por Wes Craven, figura referencial del slasher clásico, y director de la saga cinematográfica Scream, renovando con esta franquicia su propio modelo genérico y reinventado así el género slasher (Wee, 2006, p. 54); este reciente subgénero, tan prolífico en la década de los 90 y con gran influencia en la producción televisiva actual, se define del siguiente modo:

El neo slasher, como la mayoría del cine postmoderno, se caracteriza por la autoconsciencia del género, reutilizando los tópicos del slasher de los setenta y los ochenta, y añadiendo vueltas de tuerca que tratan de asustar al 
espectador, aunque este conozca perfectamente los giros que rigen el discurso de terror (García y Raya Bravo, 2015, p.30).

No obstante, el traslado del formato impide que permanezcan algunas estructuras básicas. Por un lado, la inserción de tramas personales para todos los caracteres secundarios paraliza la acción en numerosas ocasiones, ofreciendo equilibrio entre terror y romance adolescente. Por otro lado, es necesaria la introducción paulatina de nuevos personajes que ocupen el espacio de las víctimas, también con la intención de proponerlos ante la audiencia como posibles asesinos. Todas estas incorporaciones de tramas y personajes expanden narrativamente el relato, en una especie de juego que trata de confundir constantemente al espectador sobre la identidad del asesino.

Asimismo se incumplen otras reglas básicas vinculadas al subgénero, como es el traslado de roles que acaban siendo transformados y escapan del esquema original. Por ejemplo, en la serie el personaje de Brooke (Carlson Young) funciona actancialmente ${ }^{6}$ como ayudante de la protagonista, pero a la vez cumple un rol muy común dentro del cine slasher, el de "rubia tonta", compartiendo varias de sus características: se muestra un poco frívola y caprichosa, es admirada y envidiada por todos en el instituto y a su vez tiene un físico destacable, distinguiéndose por su hermoso cabello rubio; además expresa su sexualidad libremente, teniendo varias parejas íntimas a lo largo de las dos temporadas emitidas. Su personaje es equiparable al de Tatum (Rose McGowan) de la primera entrega cinematográfica de la saga, pero a diferencia de ella, que es asesinada brutalmente en dicha película, Brooke se revela como una auténtica superviviente, luchadora y valiente. Este tipo de personajes suelen ser castigados en la tradición slasher por vivir su sexualidad libremente, pero en el texto televisivo no sucede así, manteniendo al espectador en constante sorpresa ante su capacidad de subsistencia.

6. El modelo actancial estructuralista de Greimas desarrollado en Semántica estructural. Investigación metodológica (1987) considera al personaje como elemento válido por el lugar que ocupa en la narración y la contribución que realiza para que ésta avance, pudiendo ocupar seis posiciones: Sujeto, Objeto, Destinador, Destinatario, Ayudante, Oponente. 
Atendiendo a la clasificación expuesta por Wagner, la serie es una analogía con respecto al texto original que traslada, pues se plantea como una reinvención completa del texto madre. Entrando dentro de la terminología planteada para el ámbito audiovisual reciente, la serie es un reboot del concepto original, que es una de las tendencias más frecuentes dentro de las nuevas versiones o remakes. El concepto de reboot se basa en relanzar un producto con nuevas características, expresivas, formales o contextuales que sorprendan al antiguo público, o bien tratar de revivir un universo olvidado para atraer a una nuevo sector de la audiencia, sin que eso suponga el desprecio del texto primigenio (Benchichà, 2015, p. 231). En este caso, el respeto reverencial hacia el producto madre explica la razón por la que se mantienen algunos aspectos del texto original y en cambio se sustituyen otros, vinculándose al fenómeno de intertextualidad que reina en nuestros días en el ámbito audiovisual (Stam, 2001, Verevis, 2006). De este modo, la serie Scream introduce referencias y alusiones en una especie de juego nostálgico que, a la vez que recupera el texto original, construye uno nuevo diferente (Verevis, 2006, p. 23); el objetivo es parecerse, manteniendo conexiones fundamentales pero sin llegar a poder identificarse por completo.

\section{Conclusiones}

El análisis de la serie Scream revela que aunque la serie aprovecha varios tópicos asociados al género de terror, también reversiona sus códigos al ser imposibles de adaptar literalmente a un contenido serial tan prolongado, ampliando las posibilidades narrativas mucho más de lo que podían hacerlo las películas. En el ejemplo concreto de la serie, esto se traduce en cierto grado de experimentación y reinvención de las fórmulas habituales, consecuencia lógica de enfrentarse a un género que funciona habitualmente con una estructura vertical de la trama.

No obstante, la serie cumple los códigos generales del neo slasher, sobre todo en lo concerniente a la autoconsciencia del género y el bagaje de la audiencia, jugando con esas ideas preconcebidas para tratar de crear sorpresas. La disimilitud principal es que la serie concede tanta importancia al terror como 
a las problemáticas adolescentes, especialmente centradas en sus relaciones sentimentales, partiendo de una concepción voluntariamente híbrida desde el propio origen del proyecto. Sin duda, esto está estrechamente relacionado con las necesidades comerciales de la cadena de emisión, que necesita atraer a un espectro amplio, el público adolescente en general, acostumbrado a los seriales románticos.

Existe además intencionalidad y voluntariedad a la hora de desligar la franquicia cinematográfica de la serie desde la propia concepción de la adaptación, entrando dentro de las corrientes de relectura asociadas sobre todo al remake y el denominado reboot. Se evitan los nombres originales, se sustituye la icónica máscara de Ghostface, y se actualiza la narración al contexto presente en su vertiente más tecnológica, pero se mantiene la esencia del argumento, en un deliberado intento de crear algo nuevo y viejo a la vez. En definitiva, como texto expansivo del relato original, la serie Scream también está vinculada a las expectativas y el conocimiento de la audiencia, siendo más adecuado hablar de intertextualidad, en un sentido amplio, que de reboot o adaptación.

\section{Referencias bibliográficas}

Altman, R. (2000). Los géneros cinematográficos. Barcelona: Paidós.

Balló, J. y Pérez, X.(2005). Yo ya he estado aquí: ficciones de la repetición. Barcelona: Anagrama.

Benchichá López, N. Y. (2015). La tercera edad dorada de la televisión. Battlestar Galactica y las nuevas formas de pensar, hacer y consumir el drama televisivo norteamericano. Tesis Doctoral. España, Departamento de Comunicación, Universitat Ramon Llull.

Carroll, N. (1990). The Philosophy of Horror or Paradoxes of the Heart. New York: Routledge.

Clover, C. J. (1987). Her Body, Himself: Gender in the Slasher Film. Representations, No. 20, Special Issue: Misogyny, Misandry, and Misanthropy. (Autumn), 187-228.

Díaz, S. (2012). Adaptación audiovisual e hibridación discursiva. La serie Wallander como paradigma. Revista Comunicación, $\mathrm{N}^{\mathrm{0}} 10$, Vol.1, 504516.http://www.revistacomunicacion.org/pdf/n10/mesa3/o39.Adapt 
acion_audiovisual_e_hibridacion_discursiva.Las_series_Wallander como_paradigma.pdf

García, P.J. y Raya Bravo, I. (2015). Antes del psicópata televisivo. Siguiendo la pista al asesino en serie en la historia del cine. Asesinos en serie(s). Representación persuasiva del serial killer en la ficción televisiva contemporánea. Madrid: Síntesis, 17-48.

Gordillo, I. (2009) La hipertelevisión: géneros y formatos. Ecuador: Ciespal.

Greimas, A. J. (1987). Semántica estructural. Investigación metodológica. Madrid: Gredos.

Jenkins, H. (2007). The WOW Climax. Tracing the Emotional Impact of Popular Culture. New York: New York University Press.

Leeder, M. (2009). Forget Peter Vincent: Nostalgia, Self-Reflexivility, and the Genre Past in Fright Night. JPF\&T (Journal of Popular Film and Television), Vol, 36, Issue 4, 191-199.

http://www.tandfonline.com/doi/abs/10.3200/JPFT.36.4.190-199

Longworth, J. L. (2002). TV creators: Conversations with America's Top Producers of Television Drama, Volumen 2. Syracuse: University of Syracuse Press.

López Rodríguez, F.J. (2012). Modificaciones narrativas en la adaptación cinematográfica del cómic japonés. Revista Comunicación, $\mathrm{N}^{\mathrm{0}} 10$, Vol.1, 1549-1564.

http://www.revistacomunicacion.org/pdf/n10/mesa9/118.Modificaciones_n arrativas_en_la_adaptacion_cinematografica_del_comic_japones.pd f

Mittell, J. (2004). Genre and Television. From Cop Shows to Cartoons in American Culture. New York: Routledge.

Murphy, S. (2015). Scream producers explain why the original ghostface mask had to go. http://www.mtv.com/news/2180259/scream-tvmask/

Ribés Alegría, M. (2005). La hibridación de géneros y la crisis de la calidad televisiva: consejos audiovisuales en el panorama televisivo. Comunicar: Revista científica iberoamericana de comunicación y educación, $\quad \mathrm{V}$. 25. http://www.revistacomunicar.com/verpdf.php?numero=25\&articulo= 25-2005-131

Rincon, O. (2013). Los formatos audiovisuales de la identidad. En Guarinos, V. y A. Sedeño (eds.), Narrativas audiovisuales digitales. Convergencia de medios, multiculturalidad y transmedia (pp. 165192). Madrid: Fragua.

Sánchez Noriega, J. L. (2003). Historia del cine. Teoría y géneros cinematográficos, fotografía y televisión. Madrid: Alianza Editorial.

Scolari, C. A., Jiménez, M. y Guerrero, M. (2012). Narrativas transmediáticas en España: cuatro ficciones en busca de un destino cross-media en 
Comunicación $y \quad$ Sociedad, Vol.XXV, $\quad \mathrm{n}^{0} 1, \quad$ 137-163. https://dialnet.unirioja.es/servlet/articulo?codigo $=3954671$

Scolari, C. (2013). Narrativas transmedia. Cuando todos los medios cuentan. Barcelona: Deusto.

Stam, R. (2001). Teorías del cine. Barcelona: Paidós.

Todorov, T. (2005). Introducción a la literatura fantástica. México: Ediciones Coyoacán.

Tous, A. (2009). Paleotelevisión, neotelevisión y metatelevisión en las series dramáticas estadounidenses. Comunicar, $\mathrm{N}^{\circ} 33$, V. XVII, 175-183. http://www.revistacomunicar.com/index.php?contenido=detalles\&nu $\underline{\text { mero }=33 \& \text { articulo }=33-2009-21}$

Tous, A. (2010) La era del drama en televisión. Perdidos, CSI: Las Vegas, El ala oeste de la Casa Blanca, Mujeres Desesperadas y House. Barcelona: Editorial UOC.

Verevis, C. (2006). Film Remakes. Edinburgh: Edinburgh University Press.

Wagner, G. (1975). The Novel and the Cinema. London: Tantivy Press.

Wee, V. (2006). Resurrecting and Updating the Teen Slasher: The Case of Scream. Journal of Popular Film and Television, 34:2, 50-61.

Welsh, A. (2009). Sex and Violence in Slasher Horror Film: A Content Analisys of Gender Differences in the Despiction of Violence. Journal of Criminal Justice and Popular Culture, 16. http://www.albany.edu/scj/jcjpc/vol16is1/Welsh.pdf

Cómo citar: Raya Bravo, I. (2017). "Adaptando el terror cinematográfico a la serialidad televisiva. El caso de Scream”. Fotocinema. Revista científica de cine $y$ fotografía, $\mathrm{n}^{\mathrm{O}} 14, \quad$ p. 183-204. Disponible: http://www.revistafotocinema.com/ 